The trees that I see from my window appear not to have changed.

But they have. One of the tallest is broken, and now we don't remember what a great wall of green it made. Others have a disease.

The earth does not breathe enough. The hedges hardly have time to put out their new leaves before August clogs them with dust and October with smoke.

The garden's history and the city's are not of interest. We have no time to sketch the leaves or the insects or to sit in the white light hour after hour, working. The trees don't seem to have changed, they look true to their kind.

And yet they have been carried far away. Not even a cry, not even a sough is heard. This is no cause for despair, my daughter, but for understanding while together we look at the trees and you learn who your father is.

translated by

Michael Hamburger

\title{
IN MEMORIAM I
}

Once you asked me what was on my mind and I did not reply.

But it's become very difficult to talk of last things, my mother. 
In the last hours

you stared wide-eyed.

You were terrified that you would not

be able to talk any more

not even inside yourself

about the one thing.

Now the noise is so violent

so furious the shaking-up of all reality

that even down there in the end

the tremor must reach you

felt as it was in the cellars once, in the war.

I shall not have time enough to reckon up, even now

it's too late for that.

And this is the very thing

I did not know before.

Now you know it too

we know it

while about to be reborn.

translated by

Michael Hamburger

\section{IN MEMORIAM III}

The little girl crushed the mantis with a rock.

It jerked its head at each blow.

From its abdomen an omelet of seed

a stain of eaten meals.

The mandibles bit.

The knives of the claws slashed

air. One half

of an insect fulfilled itself.

translated by

Michael Hamburger 